\title{
Phenylketonuria and Hirschsprung Disease- A Report of an Unusual Neonatal Presentation
}

\author{
Nina Lenherr ${ }^{1, \dagger}{ }^{\dagger}$ Viktoria A. Pfeifle ${ }^{1, \dagger}{ }^{\dagger}$ Stefan Holland-Cunz ${ }^{1}$, Susanna H. M. Sluka ${ }^{2}$, \\ Beat Thöny ${ }^{3}$, Gabor Szinnai ${ }^{1}$, Martina Huemer ${ }^{1,3}$, Marianne Rohrbach ${ }^{3}$ and \\ Ralph Fingerhut $2,3, *$ \\ 1 University Children's Hospital, Basel 4056, Switzerland; Nina.Lenherr@ukbb.ch (N.L.); \\ Viktoria.Pfeifle@ukbb.ch (V.A.P.); Stefan.Holland-Cunz@ukbb.ch (S.H.-C.); Gabor.Szinnai@ukbb.ch (G.S.); \\ huemer.martina@googlemail.com (M.H.) \\ 2 Swiss Newborn Screening Laboratory, and Children's Research Center, University Children's Hospital, \\ Zurich 8032, Switzerland; susanna.sluka@kispi.uzh.ch \\ 3 Division of Metabolism, and Children's Research Center, University Children's Hospital, Zurich 8032, \\ Switzerland; beat.thoeny@kispi.uzh.ch (B.T.); marianne.rohrbach@kispi.uzh.ch (M.R.) \\ * Correspondence: ralph.fingerhut@kispi.uzh.ch; Tel.: +41-44-266-7732; Fax: +41-44-266-8110 \\ + These authors contributed equally to this work.
}

Received: 25 July 2017; Accepted: 25 August 2017; Published: 30 August 2017

\begin{abstract}
We describe a term born boy of non-consanguineous Swiss parents with tetrahydrobiopterine $\left(\mathrm{BH}_{4}\right)$-responsive Phenylketonuria (PKU) and Hirschsprung disease with unusual neonatal presentation. The child presented with floppiness, irritability, recurrent bilious vomiting and failure to pass meconium until 32 hours after birth, resulting in the clinical suspicion of an intoxication-type metabolic disease such as maple syrup urine disease (MSUD). Although the slightly elevated branched-chain amino acids in newborn screening on the fourth day of life initially supported the clinical suspicion of MSUD, the elevated Phenylalanine (Phe) of $650 \mu \mathrm{mol} / \mathrm{L}$, low Tyrosine (Tyr) of $30 \mu \mathrm{mol} / \mathrm{L}$, and a Phe/Tyr ratio of 22, led to the diagnosis of $\mathrm{PKU} \mathrm{BH}_{4}$-testing resulted in a significant decrease of Phe from 1011 to $437 \mu \mathrm{mol} / \mathrm{L}$ within $24 \mathrm{~h}$. Urinary pterins and dihydropteridine reductase (DHPR) activity were normal, supporting the diagnosis of $\mathrm{BH}_{4}$-responsive PKU. Dietary restriction of Phe was initiated immediately, but oral feeding turned out to be difficult because of gastrointestinal symptoms. Intestinal motility disorder was suspected due to distended abdomen, obstructive symptoms and radiological findings with dilated intestinal loops and lack of intestinal gas in the anorectal region. Hirschsprung disease was confirmed by rectal suction biopsies and treated by a laparoscopically-assisted transanal pull-through (de la Torre) procedure. The boy is additionally compound heterozygous for two mutations in the phenylalanine hydroxylase $(P A H)$ gene, which confirmed $\mathrm{BH}_{4}$-responsive PKU. It is the first case to be described in the literature of the comorbidity of PKU and Hirschsprung disease.
\end{abstract}

Keywords: Phenylketonuria; maple syrup urine disease; Hirschsprung disease; intestinal motility disorder

\section{Introduction}

Newborn screening (NBS) for phenylketonuria (PKU) was initiated in Switzerland in 1965, using the classical "Guthrie-test" [1]. Since 2005, NBS for PKU using tandem mass spectrometry is performed at the University Children's Hospital Zurich. Phenylalanine (Phe) and the phenylalanine/tyrosine (Phe/Tyr) ratio are sensitive and specific tests to detect PKU [2-4]. The main clinical features of untreated PKU are intellectual disability and seizures, which become evident during the first months of life [5]. Maple syrup urine disease (MSUD) is an acute intoxication-type metabolic disease, that often presents with recurrent vomiting, coma and sepsis-like presentation during first days of life $[6,7]$. 
Thus, clinical presentations of PKU and MSUD are very different. Hirschsprung disease (HD) is a rare congenital birth defect of the enteric nervous system characterized by the absence of neuronal ganglia in the most distal segment of the intestine. The aganglionosis leads to an intestinal motility disorder with associated symptoms such as absence of meconium pass, abdominal distention and emesis. It can occur as an isolated disease or as part of a multisystem disorder [8]. We are presenting an infant, with both PKU and HD in whom the symptoms of HD and slight elevations of branched-chain amino acids in newborn screening initially led to the suspicion of MSUD.

\section{Case Report}

A first born male child of non-consanguineous Swiss parents was referred to the neonatology department due to recurrent bilious vomiting and absent meconium pass at $32 \mathrm{~h}$ after birth at term. Clinical examination showed pale skin, delayed time to recapillarisation and a distended abdomen, resulting in the clinical suspicion of intestinal atresia or motility disorder or intoxication-type metabolic disease, e.g., MSUD. X-ray and abdominal ultrasound demonstrated dilated intestinal loops and lack of intestinal gas in the anorectal region. Laboratory tests revealed normal blood count, creatinine, c-reactive protein (CRP), blood gas analysis and electrolytes. Ketonuria or hyperammonaemia were not observed.

Dry blood spot sampling for newborn screening (NBS) performed on day 4 during parenteral feeding revealed an elevated phenylalanine level of $650 \mu \mathrm{mol} / \mathrm{L}$. Elevated plasma phenylalanine $(768 \mu \mathrm{mol} / \mathrm{L})$ and low plasma tyrosine $(31 \mu \mathrm{mol} / \mathrm{L})$ in quantitative amino acid analysis supported the tentative diagnosis of phenylketonuria but the additional slightly elevated branched-chain amino acids (leucine/isoleucine $306 \mu \mathrm{mol} / \mathrm{L}$; valine $299 \mu \mathrm{mol} / \mathrm{L}$ ) at first supported the clinical suspicion of MSUD. However, alloisoleucine was not detectable with the second-tier test, therefore MSUD could be excluded [9].

Administration of $\mathrm{BH}_{4}$ showed a significant decrease of phenylalanine level (744 to $\left.169 \mu \mathrm{mol} / \mathrm{L}\right)$ $24 \mathrm{~h}$ after administration of $20 \mathrm{mg} / \mathrm{kg} \mathrm{BH}_{4}$ on day 12 of life. DHPR activity as well as neopterin and biopterin concentrations in blood and urine were normal. Therefore, mild phenylketonuria (ORPHA79253) caused by phenylalanine hydroxylase deficiency was presumed. Genetic testing of the $P A H$ gene revealed compound heterozygosity for two mutations in the $P A H$ gene: c.612T $>G$, p.(Tyr204*) and c.1241A>G, p.(Tyr414Cys).

Mutation analysis of the parents confirmed that these two mutations are in trans. This genotype is associated with $\mathrm{BH}_{4}$-responsive PKU (www.biopku.org).

Treatment with diet was implemented subsequent to $\mathrm{BH}_{4}$ testing and as expected, the child required only mild Phe restriction. Over the next days, however, oral feeding turned out to be difficult and further gastroenterological workup indicated an intestinal motility disorder which caused recurrent vomiting and failure to thrive which triggered an increase of Phe levels. Rectal suction biopsies showed increased acetylcholinesterase staining and an absence of neuronal ganglia in all rectal biopsies, histomorphological typically for Hirschsprung disease. At 6 weeks of age, the patient underwent surgery. A laparoscopic mapping of biopsies revealed an affected zone up to the transverse colon. The aganglionotic segment was resected transanally by a pull-through procedure. Postoperatively, he recovered fully, but at the age of 3 months an intrasphincteric botulinum toxin injection was done due to recurrent obstructive symptoms. Impaired intestinal motility resulted in difficulties of feeding. Therefore, a percutaneous endoscopic gastrostomy (PEG) was inserted leading to an improvement of the feeding situation. By following a specific diet, phenylalanine values were kept stable within the targeted range (Table 1). In the follow-up visits, the patient presented in good health with full recovery from the gastrointestinal symptoms and normal neurological development. 
Table 1. Concentration of phenylalanine, tyrosine, leucine/isoleucine, and valine during the first 51 days of life (DOL); measured from dried blood spots (DBS) by tandem MS with the standard newborn screening (NBS) method; concentrations in $\mu \mathrm{mol} / \mathrm{L}$.

\begin{tabular}{|c|c|c|c|c|c|}
\hline DOL & Phe & Tyr & Leu/Ile & Val & Remarks \\
\hline 4 & 650 & 30 & 306 & 299 & \\
\hline 7 & 442 & 45 & 91 & 87 & \\
\hline 11 & 557 & 21 & 62 & 65 & \\
\hline 12 & 744 & 45 & 127 & 120 & before $\mathrm{BH}_{4}$ \\
\hline 12 & 722 & 58 & 143 & 116 & $4 \mathrm{~h}$ after $\mathrm{BH}_{4}$ \\
\hline 12 & 582 & 86 & 198 & 140 & $8 \mathrm{~h}$ after $\mathrm{BH}_{4}$ \\
\hline 12 & 403 & 80 & 162 & 119 & $12 \mathrm{~h}$ after $\mathrm{BH}_{4}$ \\
\hline 13 & 169 & $<10$ & 61 & 44 & $24 \mathrm{~h}$ after $\mathrm{BH}_{4}$ \\
\hline 14 & 117 & 15 & 172 & 163 & $48 \mathrm{~h}$ after $\mathrm{BH}_{4}$ \\
\hline 15 & 28 & 41 & 227 & 178 & \\
\hline 16 & 5 & 31 & 188 & 200 & \\
\hline 17 & 18 & 42 & 223 & 220 & \\
\hline 18 & 5 & 41 & 242 & 216 & \\
\hline 19 & 3 & 49 & 232 & 194 & \\
\hline 20 & 36 & 37 & 209 & 193 & \\
\hline 21 & 12 & 19 & 203 & 159 & \\
\hline 22 & 23 & 27 & 169 & 135 & \\
\hline 23 & 95 & 71 & 193 & 160 & \\
\hline 24 & 35 & 75 & 165 & 156 & \\
\hline 25 & 29 & 23 & 123 & 129 & \\
\hline 26 & 20 & 21 & 118 & 97 & \\
\hline 27 & 68 & 19 & 119 & 94 & \\
\hline 31 & 30 & 31 & 80 & 79 & \\
\hline 34 & 22 & 39 & 165 & 151 & \\
\hline 37 & 35 & 73 & 205 & 176 & \\
\hline 40 & 45 & 100 & 220 & 187 & \\
\hline 46 & 54 & 23 & 99 & 90 & \\
\hline 47 & 77 & 13 & 68 & 70 & \\
\hline 48 & 53 & 96 & 334 & 282 & \\
\hline 49 & 138 & 22 & 133 & 141 & \\
\hline 49 & 147 & 106 & 136 & 157 & \\
\hline 50 & 236 & 48 & 131 & 129 & \\
\hline 51 & 209 & 32 & 98 & 89 & \\
\hline
\end{tabular}

\section{Discussion}

Our case of a mild $\mathrm{BH}_{4}$-responsive PKU, detected by newborn screening, showed an initially untypical clinical presentation with gastrointestinal symptoms reminiscent of an intoxication-type metabolic disease such as MSUD. Slightly elevated branched-chain amino acids supported the initial clinical suspicion of MSUD. However, the distended abdomen, emesis and delayed passage of meconium were also highly indicative of Hirschsprung disease, a congenital disorder of the enteric nervous system. Therefore, the patient was evaluated by an interdisciplinary team of paediatric surgeons, neonatologists and paediatric endocrinologists. PKU was confirmed by persistently elevated phenylalanine blood concentrations. However, the elevated phenylalanine and branched-chain amino acids in the initial NBS specimen could have also been a result of the parenteral nutrition. Rectal suction biopsies showed aganglionosis up to the transverse colon. The concurrence of PKU and Hirschsprung disease has never been described in literature before and made the diagnosis of PKU initially difficult.

A multicentre cohort study described 21 co-existent conditions in a cohort of $30 \mathrm{PKU}$ patients with six cases involving the gastrointestinal tract. The co-existent gastrointestinal disorders were Crohn disease, ulcerative colitis $(n=2)$, eosinophilic colitis, cystic fibrosis and oesophageal stenosis. A possible genetic background linking PKU to these disorders has not yet been elucidated [10]. None of these conditions, however, involved the enteric nervous system. Hirschsprung disease occurs as an isolated 
phenotype in $70 \%$ of cases, but can also be associated with a variety of congenital abnormalities and chromosomal syndromes [11]. It is characterized by a variable pattern of inheritance which has not yet been fully explored. Genes with a crucial role in the pathogenesis of HD include RET [12], Endothelin B receptor [13] and SOX [14]. Comorbidities such as Waardenburg syndrome, MEN2, Mowat-Wilson Syndrome, Down Syndrome and other chromosomal anomalies have been reported [15]. Concerning other metabolic disorders, HD in associations with Smith-Lemli-Opitz [11] and Bardet-Biedl syndrome has been described [16]; an association with PKU has never been reported. As the pathogenesis and genetics of Hirschsprung disease are still to be discovered, reporting of associated comorbidities is of great value and importance.

In our case, the concurrence of PKU and Hirschsprung disease has not only made the diagnosis challenging, but also influenced the management. Dietary treatment was more difficult to manage due to the intestinal motility disorder and obstructive symptoms. It is essential to integrate a multidisciplinary team to provide the best care and treatment options for patients with such comorbidity constellations.

\section{Conclusions}

We present a case of $\mathrm{BH}_{4}$-responsive $\mathrm{PKU}$ where Hirschsprung disease and not an intoxication-type metabolic disease caused the recurrent vomiting and feeding disorder. So, comorbidity can complicate the interpretation of newborn screening results.

Acknowledgments: We wish to thank Mirjam Weibel for technical assistance in the mutation analysis of the PAH gene.

Author Contributions: Nina Lenherr, Viktoria A. Pfeifle, Stefan Holland-Cunz, Susanna H.M. Sluka, Beat Thöny, Gabor Szinnai, Martina Huemer, Marianne Rohrbach and Ralph Fingerhut have participated in the concept and design, analysis and interpretation of data, drafting or revising of the manuscript; and they have approved the manuscript as submitted.

Conflicts of Interest: The authors declare no conflict of interest.

\section{References}

1. Guthrie, R.; Susi, A. A simple phenylalanine method for detecting PKU in large populations of newborn infants. Pediatrics 1963, 32, 338-343. [PubMed]

2. Schulze, A.; Kohlmueller, D.; Mayatepek, E. Sensitivity of electrospray-tandem massspectrometry using the phenylalanine/tyrosine-ratio for differential diagnosis ofhyperphenylalaninemia in neonates. Clin. Chim. Acta 1999, 283, 15-20. [CrossRef]

3. Schulze, A.; Lindner, M.; Kohlmuller, D.; Olgemoller, K.; Mayatepek, E.; Hoffmann, G.F. Expanded newborn screening for inborn errors of metabolism by electrospray ionization-tandem mass spectrometry: Results, outcome, and implications. Pediatrics 2003, 111, 1399-1406. [CrossRef] [PubMed]

4. Wilcken, B.; Wiley, V.; Hammond, J.; Carpenter, K. Screening newborns for inborn errors of metabolism by tandem mass spectrometry. N. Engl. J. Med. 2003, 348, 2304-2312. [CrossRef] [PubMed]

5. Blau, N.; van Spronsen, F.J.; Levy, H.L. Phenylketonuria. Lancet 2010, 376, 1417-1427. [CrossRef]

6. Strauss, K.A.; Puffenberger, E.G.; Morton, D.H. Maple Syrup Urine Disease. In GeneReviews; Pagon, R.A., Adam, M.P., Ardinger, H.H., Wallace, S.E., Amemiya, A., Bean, L.J.H., Bird, T.D., Fong, C.T., Mefford, H.C., Smith, R.J.H., et al., Eds.; University of Washington: Seattle, WA, USA, 2013.

7. Abiri, M.; Talebi, S.; Uitto, J.; Youssefian, L.; Vahidnezhad, H.; Shirzad, T.; Salehpour, S.; Zeinali, S. Co-existence of phenylketonuria either with maple syrup urine disease or Sandhoff disease in two patients from Iran.: Emphasizing the role of consanguinity. J. Pediatr. Endocrinol. Metab. 2016, 29, 1215-1219. [CrossRef] [PubMed]

8. Parisi, M.A. Hirschsprung Disease Overview. In GeneRevieww; Pagon, R.A., Adam, M.P., Ardinger, H.H., Wallace, S.E., Amemiya, A., Bean, L.J.H., Bird, T.D., Fong, C.T., Mefford, H.C., Smith, R.J.H., et al., Eds.; University of Washington: Seattle, WA, USA, 2015. 
9. Fingerhut, R.; Röschinger, W.; Heck, M. A rapid and sensitive UPLC-MS/MS-method for the separation and quantification of branched-chain amino acids from dried blood samples of patients with maple syrup urine disease (MSUD). Int. J. Neonatal Screen 2016, 2, 2. [CrossRef]

10. MacDonald, A.; Ahring, K.; Almeida, M.F.; Belanger-Quintana, A.; Blau, N.; Burlina, A.; Cleary, M.; Coskum, T.; Dokoupil, K.; Evans, S.; et al. The challenges of managing coexistent disorders with phenylketonuria: 30 cases. Mol. Genet. Metab. 2015, 116, 242-251. [CrossRef] [PubMed]

11. Moore, S.W. Chromosomal and related Mendelian syndromes associated with Hirschsprung's disease. Pediatr. Surg. Int. 2012, 28, 1045-1058. [CrossRef] [PubMed]

12. Lyonnet, S.; Bolino, A.; Pelet, A.; Abel, L.; Nihoul-Fékété, C.; Briard, M.L.; Mok-Siu, V.; Kaariainen, H.; Martucciello, G.; Lerone, M.; et al. A gene for Hirschsprung disease maps to the proximal long arm of chromosome 10. Nat. Genet. 1993, 4, 346-350. [CrossRef] [PubMed]

13. Puffenberger, E.G.; Hosoda, K.; Washington, S.S.; Nakao, K.; deWit, D.; Yanagisawa, M.; Chakravart, A. A missense mutation of the endothelin-B receptor gene in multigenic Hirschsprung's disease. Cell 1994, 79, 1257-1266. [CrossRef]

14. Kelsh, R.N. Sorting out Sox10 functions in neural crest development. Bioessays 2006, 28, 788-798. [CrossRef] [PubMed]

15. Patterson, K.; Toomey, K.E.; Chandra, R.S. Hirschsprung disease in a 46,XY phenotypic infant girl with Smith-Lemli-Opitz syndrome. J. Pediatr 1983, 103, 425-427. [CrossRef]

16. Islek, I.; Küçüködük, S.; Erkan, D.; Bernay, F.; Kalayci, A.G.; Görk, S.; Kandemir, B.; Gürses, N. Bardet-Biedl syndrome: Delayed diagnosis in a child with Hirschsprung disease. Clin. Dysmorphol. 1996, 5, 271-273. [CrossRef] [PubMed]

(C) 2017 by the authors. Licensee MDPI, Basel, Switzerland. This article is an open access article distributed under the terms and conditions of the Creative Commons Attribution (CC BY) license (http:/ / creativecommons.org/licenses/by/4.0/). 